\title{
UJI ORGANOLEPTIK CRACKERS PISANG TONGKA LANGIT
}

\author{
Organoleptic Test of Instan Porridge Made from Tongka Langit Flour
}

\section{Priscillia Picauly* dan Gilian Tetelepta}

\author{
Jurusan Teknologi Hasil Pertanian Fakultas Pertanian Universitas Pattimura \\ Jl. Ir. M. Putuhena Kampus Poka Ambon 97233. \\ * Penulis Korespondensi: E-mail: priscilia_pic@yahoo.com
}

\begin{abstract}
Tongka langit banana is one of the particular indigenous fruits in Maluku. Tongka langit banana contain high nutrients including pro vitamin A and has a lot of health benefits. However, it is also a perishable product, and would deteriorate if not processed or not completely consumed. Therefore, this banana should be processed into diverse products. It can be processed into intermediate product such as flour, which can be further applied in crackers making. Variables observed on crackers including taste, aroma, colour, texture and overall likeness. Results showed that crackers made from $40 \%$ banana flour and $60 \%$ wheat flour were mostly liked by panelists in terms of taste, colour, aroma, texture and overall likeness.
\end{abstract}

Keywords: tongka langit banana, flour, crackers, organoleptic

\begin{abstract}
ABSTRAK
Pisang tongka langit merupakan salah satu jenis buah lokal yang terdapat di Maluku. Pisang tongka langit kaya akan kandungan gizi antara lain mengandung provitamin A dan mempunyai manfaat kesehatan. Namun pisang tongka langit mudah mengalami kerusakan jika tertunda pengolahannya atau tidak habis dikonsumsi, oleh karena itu perlu dilakukan upaya diversifikasi terhadap pisang tongka langit. Pisang tongka langit dapat diolah menjadi bahan setengah jadi berupa tepung yang dapat diaplikasikan menjadi produk crackers. Pengamatan yang dilakukan pada crackers yaitu uji organoleptik yang meliputi rasa, aroma, warna, tekstur dan tingkat kesukaan secara keseluruhan. Hasil penelitian menunjukkan bahwa crackers tepung pisang tongka langit $40 \%$ : tepung terigu $60 \%$ memiliki rasa, warna, aroma, tekstur dan tingkat penerimaan secara keseluruhan yang disukai panelis.
\end{abstract}

Kata Kunci: pisang tongka langit, tepung, crackers, organoleptik

\section{PENDAHULUAN}

Pisang "Tongka Langit" (Musa troglodytarum) merupakan salah satu jenis buah lokal yang terdapat di Maluku. Pisang tongka langit memiliki tandan buah menuju ke atas sehingga seolah-olah sedang menopang langit (Dinas Pertanian, 2006).

Pisang tongka langit berdasarkan ukurannya terdiri dari 2 jenis yaitu berukuran panjang dan pendek, warna kulit buahnya kemerahan dengan bintik-bintik hitam, sedangkan daging buahnya berwarna kuning oranye, agak masam rasanya tetapi agak manis bila buahnya benar-benar masak. Tekstur daging buahnya lembut dan empuk (Heyne, 1988 dalam Samson et al. (2013).

Pisang tongka langit mengandung kadar provitamin A dan total karotenoid yang sangat tinggi, yaitu mencapai $6360 \mu \mathrm{g} / 100 \mathrm{~g}$. Kandungan karotenoid berperan penting dalam mencegah penyakit manusia, termasuk penyakit kardiovaskular, kanker dan penyakit kronis lainnya Englberger (2003) dalam Samson et al. (2013). 
Berdasarkan hasil penelitian Tetelepta et al (2005), pisang tongka langit segar mengandung tanin sebesar 0,269\%. Adanya tanin dapat menentukan cita rasa sehingga mempengaruhi penerimaan konsumen dalam mengonsumsi pisang tongka langit.

Di Maluku pisang tongka langit selain diolah secara tradisional yaitu dengan cara dibakar atau dikukus, juga diolah menjadi bahan setengah jadi berupa tepung yang dapat disubtitusi dengan jenis tepung lain untuk pembuatan biskuit (Mailoa, 2012), bubur instan (Picauly dan Tetelepta, 2015), dan juga dapat diaplikasikan pada produk crackers.

Crackers adalah biskuit atau wafer renyah dan tipis yang terbuat dari tepung terigu, lemak dan garam dan difermentasi dengan yeast serta adonan dibuat berlapis-lapis, kemudian dipotong dan dipanggang (Manley, 2001). Crackers terbagi menjadi dua jenis yaitu flacky crackers dan non flacky crackers. Flaky crackers merupakan produk yang berbentuk pipih dengan rasa lebih mengarah ke asin dan renyah serta bila dipatahkan penampang potongannya berlapis-lapis (Driyani, 2007 dalam Afianti dan Indrawati, 2015). Non flaky crackers merupakan pengembangan dari produk crackers yang berlapis-lapis (flaky crcakers) yang memiliki struktur tidak berlapis-lapis yang bagian luarnya lebih masif dan padat kalori.

\section{METODE PENELITIAN}

\section{Bahan}

Bahan untuk pembuatan tepung pisang tongka langit adalah pisang tongka langit panjang mentah dan asam sitrat. Bahan untuk pembuatan crackers adalah tepung pisang tongka langit, tepung terigu, gula, garam, margarin, cmc, baking powder, dan air.

\section{Pelaksanaan Penelitian}

\section{Pembuatan Tepung Pisang Tongka Langit (Loypimai dan Moongngarm, 2015)}

Pisang tongka langit dikupas kulitnya dan dicuci dengan air bersih untuk menghilangkan kotoran yang menempel, pisang diiris tipis-tipis atau disawut untuk memperluas permukaan sehingga mempermudah pada proses selanjutnya yaitu pengeringan, irisan pisang selanjutnya dicelupkan dalam larutan asam sitrat $(0,3 \% \mathrm{w} / \mathrm{w})$ selama 10 menit untuk mereduksi pencoklatan enzimatik, irisan pisang dikeringkan dalam cabinet dryer pada suhu $55^{\circ} \mathrm{C}$ selama 6 jam, irisan pisang kering kemudian digiling/ditepungkan dan diayak menggunakan ayakan 80 mesh untuk mendapatkan tepung pisang tongka langit.

\section{Pembuatan Crackers}

Pada pembuatan crackers, disiapkan campuran tepung pisang tongka langit dan tepung terigu sesuai perlakuan (20\%:80\%, 40\%:60\%, 60\%:40\%, dan 80\%:20\%). Bahan kering berupa tepung pisang tongka langit, tepung terigu, garam 3 $\mathrm{g}$, margarin $30 \mathrm{~g}, \mathrm{CMC} 2 \mathrm{~g}$, dan baking powder 0,8 g dicampur menjadi satu. Air sebanyak $40 \mathrm{~mL}$ dan gula $10 \mathrm{~g}$ dimixer hingga membentuk emulsi. Emulsi dimasukan dalam bahan kering dan dicampur hingga membentuk adonan kalis. Adonan kemudian ditutup dengan plastik wraping dan didiamkan selama 30 menit. Adonan yang telah didiamkan selanjutnya dipipihkan dengan rolling pin dan dicetak dengan ukuran seragam. Panggang pada suhu $170^{\circ} \mathrm{C}$ selama 10 menit. Setelah itu didinginkan selama 5 menit pada suhu ruang. Crackers kemudian dibungkus dalam plastik dan disimpan pada suhu ruang.

\section{Analisis Organoleptik}

Uji organoleptik meliputi rasa, aroma, warna, tekstur, dan tingkat penerimaan secara keseluruhan.

\section{HASIL DAN PEMBAHASAN}

\section{Rasa}

Rasa merupakan faktor yang penting dari produk suatu makanan di samping warna, aroma, tekstur dan konsistensi bahan yang akan mempengaruhi cita rasa yang ditimbulkan oleh bahan makanan tersebut.

Pada Gambar 1 terlihat bahwa dari 25 panelis yang memberikan penilaian terhadap crackers tersubtitusi pisang tongka langit 20 dan $40 \%$ menunjukkan rasa yang disukai panelis $(2,87$ dan 2,72 ) sedangkan crackers tersubtitusi pisang tongka langit 60 dan $80 \%$ menunjukkan rasa yang agak disukai panelis $(2,47$ dan 2,49).

Hal ini menunjukkan semakin sedikit penggunaan tepung pisang atau semakin banyak tepung terigu yang ditambahkan menghasilkan crackers dengan rasa yang lebih disukai panelis. 
Hasil yang sama juga ditunjukkan oleh penelitian Owusu et al. (2011) dimana rasa crackers yang terbuat dari tepung terigu lebih disukai oleh panelis dibanding crackers ubi jalar.

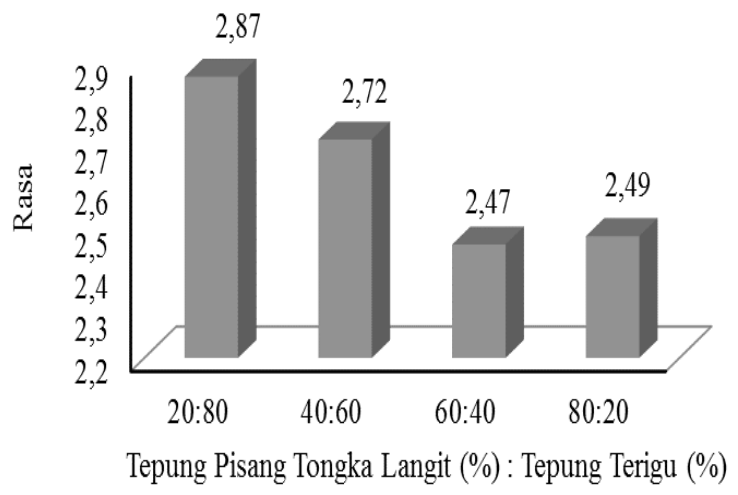

Gambar 1. Pengaruh Formulasi Tepung Pisang Tongka Langit dan Tepung Terigu Terhadap Rasa Crackers

\section{Warna}

Pada Gambar 2 terlihat bahwa dari 25 panelis yang memberikan penilaian terhadap crackers tersubtitusi pisang tongka langit 20 dan $40 \%$ menunjukkan warna yang disukai panelis (2,95 dan 2,97), sedangkan crackers tersubtitusi pisang tongka langit 60 dan $80 \%$ menunjukkan warna yang agak disukai panelis $(2,48$ dan 2,48$)$.

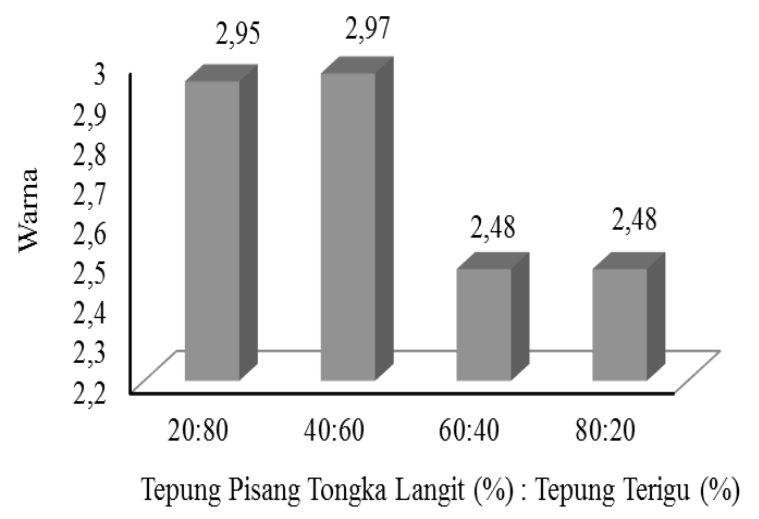

Gambar 2. Pengaruh Formulasi Tepung Pisang Tongka Langit dan Tepung Terigu Terhadap Warna Crackers

Berdasarkan Gambar 2 terlihat bahwa semakin tinggi subtitusi tepung pisang tongka langit (60 dan 80\%) kesukaan panelis terhadap warna semakin rendah.

\section{Aroma}

Pada Gambar 3 terlihat bahwa dari 25 panelis yang memberikan penilaian terhadap crackers tersubtitusi pisang tongka langit 20, 40, 60, 80\% untuk semua perlakuan menunjukkan aroma yang disukai panelis $(2,95,2,83,2,56$, dan 2,64).

Berdasarkan pengujian organoleptik terlihat bahwa tidak ada perbedaan pada tingkat kesukaan terhadap aroma crackers pisang tongka langit untuk semua perlakuan karena panelis rata-rata memilih suka untuk semua perlakuan. Hal ini menunjukkan bahwa secara keseluruhan crackers pisang tongka langit memiliki aroma yang dapat diterima oleh panelis.

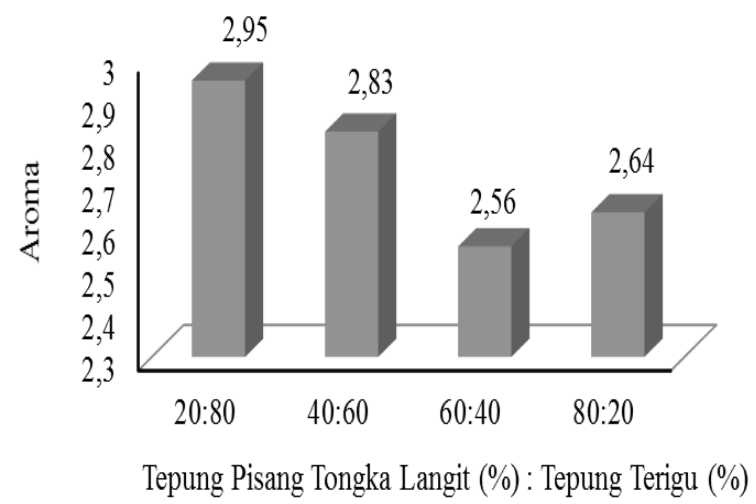

Gambar 3. Pengaruh Formulasi Tepung Pisang Tongka Langit dan Tepung Terigu Terhadap Aroma Crackers

\section{Tekstur}

Pada Gambar 4 terlihat bahwa dari 25 panelis yang memberikan penilaian terhadap crackers tersubtitusi pisang tongka langit 20, 40, 60, 80\% untuk semua perlakuan menunjukkan tekstur yang disukai panelis $(2.59,2.81,2.68$, dan 2.59). Tekstur crackers tersubtitusi tepung pisang tongka langit normal sesuai dengan SNI (1992).

Berdasarkan pengujian organoleptik terlihat bahwa tidak ada perbedaan pada tingkat kesukaan tekstur crackers pisang tongka langit untuk semua perlakuan karena panelis rata-rata memilih suka untuk semua perlakuan. Crackers tersubtitusi pisang tongka langit bertekstur renyah (crispiness) dan tidak terlalu keras (firmness) sehingga tidak terlalu lama untuk dikunyah (chewyness). Hasil penelitian ini sesuai dengan yang dilaporkan oleh Owusu et al. (2011), bahwa crakcers yang dibuat dari tepung gandum memiliki tekstur renyah dan tidak terlalu keras serta diharapkan tidak terlalu 
lama untuk dikunyah. Manley (2000) menyatakan bahwa tekstur dan pengembangan crackers diperoleh dari suhu pemanggangan yang tinggi pada awal pemanggangan dan kemudian suhunya diturunkan untuk mengeringkan crackers tanpa menimbulkan kegosongan, selama pemanggangan laminasi akan terangkat dan terpisah sehingga dihasilkan crackers yang berlapis dan renyah.

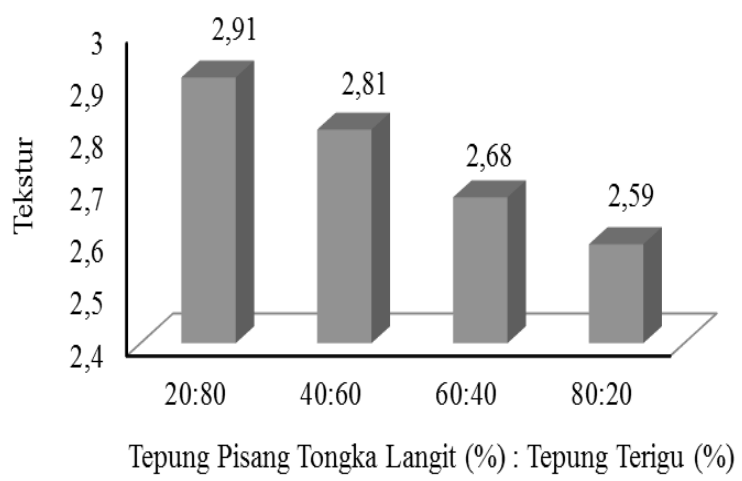

Gambar 4. Pengaruh Formulasi Tepung Pisang Tongka Langit dan Tepung Terigu Terhadap Tekstur Crackers

\section{Tingkat Penerimaan Secara Keseluruhan}

Pada Gambar 5 terlihat bahwa dari 25 panelis yang memberikan penilaian terhadap crackers tersubtitusi pisang tongka langit didapati bahwa perlakuan formulasi tepung pisang 20, 40, 60, dan $80 \%$ menunjukkan tingkat kesukaan yang dipilih panelis yaitu suka $(2.91,2.92,2.57$ dan 2.76).

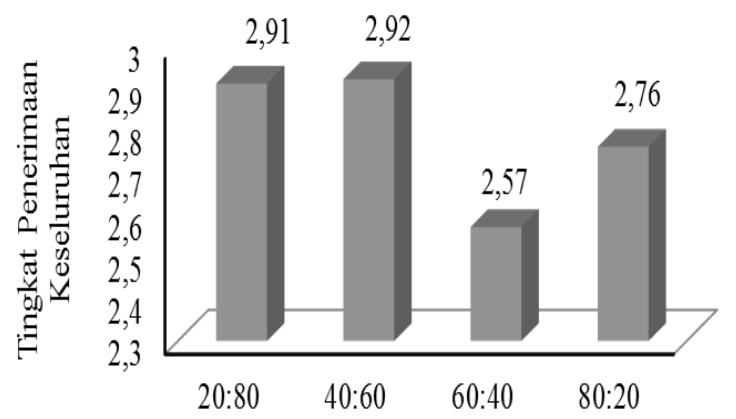

Tepung Pisang Tongka Langit (\%) : Tepung Terigu (\%)

Gambar 5. Pengaruh Formulasi Tepung Pisang Tongka Langit Dan Tepung Terigu Terhadap Tingkat Kesukaan Crackers

Hasil penilaian uji organoleptik berdasarkan empat parameter pengujian (warna, aroma, rasa dan tekstur), menunjukkan bahwa tingkat kesukaan panelis terhadap crackers tersubtitusi tepung pisang tongka langit rata-rata memilih suka dibandingkan yang lainnya, terutama pada parameter aroma dan tekstur. Sehingga hal ini berkorelasi dengan tingkat kesukaan penerimaan panelis secara keseluruhan terhadap crackers tersubtitusi tepung pisang tongka langit yang lebih memilih suka untuk semua perlakuan.

\section{KESIMPULAN}

Berdasarkan hasil penelitian terhadap uji organoleptic, crackers yang tersubtitusi pisang tongka langit $40 \%$ : tepung terigu $60 \%$ memiliki rasa, warna, aroma, tekstur dan tingkat penerimaan secara keseluruhan disukai oleh panelis.

\section{DAFTAR PUSTAKA}

Afianti, F. dan V. Indrawati. 2015. Pengaruh penambahan tepung ikan Gabus (Ophiocephalus striatus) dan air terhadap sifat organoleptik crackers. Ejournal boga 4: 46-55

Dinas Pertanian. 2006. Pisang Tongka Langit. Dinas Pertanian Provinsi Maluku. Ambon.

Loypimai, P. and A. Moongngarm. 2015. Utilization of pregelatinized banana flour as a functional ingredient in instant porridge. Food Science Technology 52: 311-318.

Mailoa, M. 2012. Pengembangan pisang tongka langit (Musa troglodytarum) menjadi biskuit. Jurnal Ekologi dan Sains 1: 1-9.

Manley, D. 2000. Technology of Biscuit, Crackers, and Cookies, Woodhead Publishing Limited, Third Edition, Chapter 3, Savory or Snack Crackers, New York, NY, 247-248.

Mir, A.A., S.J. Don Bosco, M.A. Shah, S. Santhalakshmy, and M.M. Mir. 2017. Effect of apple pomace on quality characteristics of brown rice based cracker. Journal of Saudi Society of Agricultural Science 16: 25-32.

Owusu, D., I. Oduro, and W.O. Ellis. 2011. Development of crackers from cassava and sweet potato flours using Moringa oliefera and Ipomea batatas leaves as fortificant. American Journal of Food and Nutrition 1: 114-122.

Picauly, P. dan G. Tetelepta. 2015. Karakteristik kimia bubur instan tersubtitusi tepung pisang tongka langit. Agroforestri 10: 122-126.

Samson, E., E.T. Apituley, dan D. Wakano. 2013. Analisa Lama Waktu Pemanasan Terhadap 
Stabilitas Pigmen Karotenoid Buah Pisang Tongka Langit (Musa troglodytarum) Ukuran Panjang. Prosiding FMIPA Universitas Pattimura. ISBN: 978-602-97522-0-5.

[SNI] Standar Nasional Indonesia. 1995. SNI Crackers. 01-2973-1992.
Tetelepta, G., J. Talahatu, dan S. Palijama. 2015. Pengaruh cara pengolahan terhadap sifat fisikokimia pisang tongka langit (Musa troglodytarum). Agritekno 4: 14-18. 